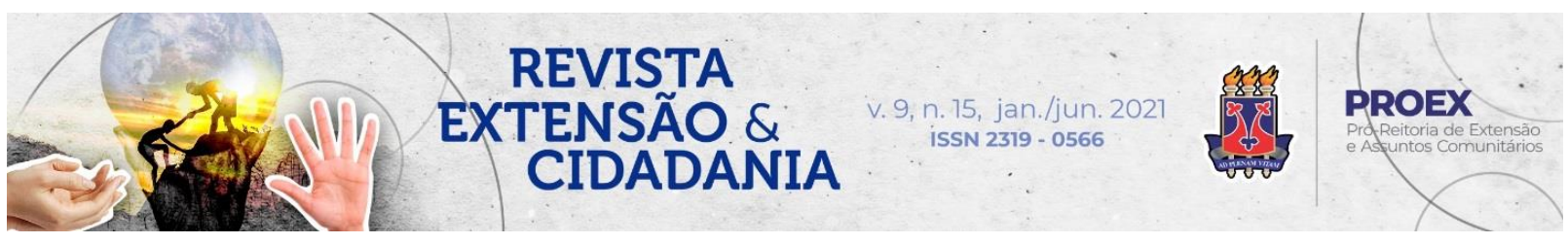

DOI: $10.22481 /$ recuesb.v9i15.8714

\title{
“QUINTAIS DE MEL”: A CRIAÇÃO DE ABELHAS SEM FERRÃO COMO FERRAMENTA DE EDUCAÇÃO AMBIENTAL
}

\section{"Honey yard": the creation of stingless bees as an environmental education tool}

\author{
Eduardo Alberto Felippsen ${ }^{1}$ \\ Tiago Amaral Silva ${ }^{2}$ \\ Sônia Maria Mandotti ${ }^{3}$ \\ Daniel Ferreira Simão ${ }^{4}$ \\ Gabriela Martines Gimenes ${ }^{5}$
}

\begin{abstract}
Resumo: O Projeto de Extensão "Quintais de Mel” é desenvolvido no Instituto Federal do Paraná, em Assis Chateaubriand - PR. Tem por objetivo promover a educação ambiental em escolas e comunidade por meio da apresentação de técnicas para o manejo das abelhas nativas sem ferrão. De modo geral, o Quintais de Mel está organizado para promover a preservação das espécies por meio de quatro etapas que consistem na metodologia do projeto. Primeiro, a estruturação de um meliponário didático para manejo das colônias das abelhas sem ferrão. Segundo, a promoção de ações educativas nas escolas do município de Assis Chateaubriand, como oficinas e palestras sobre a temática em questão. Terceira, estimular a população atendida a criar abelhas nos próprios quintais de suas casas. A última etapa, trata-se da capacitação de pessoas interessadas na criação de abelhas sem ferrão e na produção de pasto melitófilo. Como resultados parciais, destaca-se o canal do YouTube e o site do projeto, os quais apresentam conteúdos audiovisuais produzidos com foco nos estudantes e comunidade, públicos alvo do projeto. Espera-se com o retorno das atividades presenciais no IFPR, que estudantes das escolas do município visitem o meliponário didático e tenham experiências com o manejo e cultura de preservação das abelhas nativas sem ferrão.
\end{abstract}

Palavras-chave: Polinizadores. conservação. sustentabilidade.

\footnotetext{
${ }^{1}$ Mestre em Ensino. Professor do Instituto Federal do Paraná, Assis Chateaubriand, Paraná, Brasil. Orcid: 0000-0002-3102-0093 E-mail: eduardo.felippsen@ifpr.edu.br

${ }^{2}$ Mestre em Educação. Professor do Instituto Federal do Paraná, Assis Chateaubriand, Paraná, Brasil.

Orcid: 0000-0001-5101-8487 E-mail: tiago.amaral@ifpr.edu.br

${ }^{3}$ Engenheira Agrônoma. Professora do Instituto Federal do Paraná, Assis Chateaubriand, Paraná, Brasil. Orcid: 0000-0002-1452-1371 E-mail: sonia.mandotti@ifpr.edu.br

${ }^{4}$ Estudante do curso Técnico em Informática, do Instituto Federal do Paraná, Assis Chateaubriand, Paraná,

Brasil. Orcid: 0000-0003-3189-9840 E-mail: danielferreirasimao@gmail.com

${ }^{5}$ Estudante do curso de Licenciatura em Ciências Biológica, do Instituto Federal do Paraná, Assis

Chateaubriand, Paraná, Brasil. Orcid: 0000-0003-1701-708X E-mail:gabiparaifpr@gmail.com
} 
Abstract: "Quintais de Mel" is a comunite projects developed by the Instituto Federal do Paraná in Assis Chateaubriand - Paraná - Brazil. "Quintais de Mel" projetc, wich can be translated to "honey yards". The objective is to promote environmental education in schools and the community in general and then contribute to the preservation of brazilian native stingless bees. In general, Quintais de Mel is organized to promote the preservation of species through four stages that consist of the project's methodology. First, the structuring of a didactic meliponary for the management of stingless bees colonies. Second, the promotion of educational actions in schools in the municipality of Assis Chateaubriand, such as workshops and lectures on the topic in question. Third, encourage the population served to raise bees in their own backyards. The last step is the training of people interested in the creation of stingless bees and the production of melitophilous pasture. As partial results, the YouTube channel and the project website stand out, which present audiovisual content produced with a focus on students and the community, the project's target audiences. It is expected with the return of activities in person at the IFPR, that students from schools in the city will visit the educational meliponary and have experience with the management and preservation culture of native stingless bees.

Keywords: Pollinators. conservation. sustainability.

\section{Introdução: O que é o “Quintais de Mel”?}

O presente texto trata de um relato de experiência do Projeto de Extensão "Quintais de Mel", que teve sua origem com algumas atividades relacionadas à criação de abelhas nativas sem ferrão (ASF) realizadas no Instituto Federal do Paraná, Campus Assis Chateaubriand, a partir de agosto de 2019. O objetivo principal do “Quintais de Mel” é promover a educação ambiental em escolas e comunidade em geral para então contribuir com a preservação das ASF.

As abelhas exercem um papel fundamental na manutenção do ecossistema, representam um número significativo na polinização de árvores nativas que produzem frutos e alimentam diversas espécies de animais. A polinização promovida por estes insetos também está presente na produção direta de alimentos para humanos. Em suma, é um ciclo de manutenção da vida, as abelhas e outros insetos polinizam; as plantas produzem alimentos e estes alimentos servem a outros seres vivos.

Segundo Palumbo (2015) existem aproximadamente 300 espécies de abelhas identificadas no mundo, a maioria presentes em regiões tropicais do planeta. O Brasil, por abrigar grande parte destas abelhas, a sua preservação se torna imprescindível, e para contribuir com a preservação destas espécies, o projeto foi criado para promover a educação ambiental, cuja própria população seja a protagonista do processo. O nome "Quintais de Mel” vem ao

Revista Extensão \& Cidadania, v. 9, n. 15, p. 187-198, jan./jun. 2021. 
encontro desta metodologia, de fato, é contribuir para que cada cidadão possua um ambiente apropriado para receber uma colônia de abelha em casa, o que abre uma série de possibilidades para promover a educação ambiental.

Os membros participantes da organização do projeto são os servidores e estudantes do IFPR - Assis Chateaubriand, que atuam diretamente nos cursos de Ensino Médio Integrado e no curso de Ciência Biológicas deste campus. Além de ser uma das trilhas de aprendizagem dos estudantes, o foco do projeto está atrelado às possibilidades de trabalho com temas transversais dentro das instituições de educação básica conforme prevê os Parâmetros Curriculares Nacionais com a temática "Educação ambiental”.

Atualmente vários conteúdos estão sendo produzidos enquanto persistir as recomendações de isolamento social, para conter a pandemia provocada pelo Coronavirus. Portando, a maioria das atividades pelo que se apresenta nos resultados, são atividades mediadas pelas tecnologias e as poucas práticas presenciais, ocorreram respeitando as normas de biossegurança (BRASIL, 1998).

\section{Fundamentação teórica}

O Quintais de Mel tem uma perspectiva com a preservação e reconstrução da sustentabilidade do ecossistema. Sustentabilidade, é entendido por Ferreira (2010) como uma forma de utilizar o ambiente sem causar impactos, ou ao menos alterar o mínimo as suas potencialidades. Corroborando ao conceito, Boff (2012) ressalta que sustentabilidade:

[...] representa a tendência dos ecossistemas ao equilíbrio dinâmico, à cooperação e à coevolução, e responde pelas interdependências de todos com todos, garantindo a inclusão de cada um, até dos mais fracos. Se esta compreensão for correta, então fica claro que sustentabilidade e desenvolvimento configuram uma contradição nos próprios termos. Eles têm lógicas que se autonegam: uma privilegia o indivíduo, a outra o coletivo; uma enfatiza a competição, a outra a cooperação; uma a evolução do mais apto, a outra a coevolução de todos juntos e inter-relacionados. (BOFF, 2012, p. 46)

Neste ponto, Boff (2012) leva-nos ao pensamento de que a sustentabilidade dentro dos moldes atuais, caminha para um antagonismo estrutural que se propõe um conceito mais integrador de sustentabilidade, reforçando as ideias de construção de um novo paradigma civilizatório e de não restrição da ecologia ao ambientalismo puro e simples. O autor ainda menciona que o conceito de sustentabilidade ganhou luz a partir da Conferência de 1972, em

Revista Extensão \& Cidadania, v. 9, n. 15, p. 187-198, jan./jun. 2021. 
Estocolmo, e do Relatório Brundtland, Our Common Future, preparado pela Comissão Mundial sobre Meio Ambiente e Desenvolvimento, em 1987, quando foi pela primeira vez formalizado o conceito de Desenvolvimento Sustentável (BOFF, 2012).

Neste ínterim, a sustentabilidade pode estar no simples ato de criar Abelhas Sem Ferrão (ASF) em ambiente urbano que, aliás, está se tornando um hábito de muitos cidadãos pelo Brasil. Sabe-se que, desde sejam tomados alguns cuidados com a segurança tanto do criador como dos animais, esta é uma atitude que vem contribuindo para a sobrevivência de algumas espécies nativas.

A criação de ASF está reconhecida e regulamentada pela Resolução no 496, publicada no Diário Oficial da União, em 19 de agosto de 2020 (BRASIL, 2020), que, determina algumas regras para o uso ou manejo sustentável de abelhas-nativas-sem-ferrão ou meliponicultura, as quais este Projeto segue o cumprimento da legislação vigente, como também garante o bem estar desses animais. É válido destacar que todas as colônias que estão senso utilizadas no Projeto, originam-se dos meios legais, conforme a Resolução CONAMA nº 496/2020 (BRASIL, 2020) e a Portaria IAP nº 006/2019 (PARANÁ, 2019).

As colônias são obtidas por meio de capturas dentro dos padrões normativos e/ou adquiridos de Meliponários devidamente cadastrados na Agência de Defesa Agropecuária do Paraná (ADAPAR). Além do mais, todos os animais foram devidamente cadastrados neste órgão competente, em nome do coordenador do projeto. Diante disso, os animais registrados, já estão regulamentados para o manejo, conforme determina a legislação (BRASIL, 2020; PARANÁ, 2019).

Para Palumbo (2015), de todas as espécies de abelhas no mundo, aproximadamente 100 estão ameaçadas de extinção e uma das possíveis causas são os desmatamentos. Os ninhos de várias espécies de ASF são feitos em ocos de árvores com troncos mais espessos. Portanto, "as queimadas de matas nativas que representam parte do habitat natural das abelhas e o uso de agrotóxicos na produção de alimentos se apresentam como os principais fatores de extermínio das espécies”, destaca PALUMBO (2015, p. 10).

A degradação de habitats naturais para o uso da terra ou para a ocupação humana, bem como a ação dos agrotóxicos, estão entre as principais dificuldades encontradas para a conservação das espécies polinizadoras, segundo Rosa et al. (2017). ROSA et al. Os autores ainda enfatizam que as queimadas, o desmatamento e a habitual invasão do habitat natural das

Revista Extensão \& Cidadania, v. 9, n. 15, p. 187-198, jan./jun. 2021. 
abelhas pelo ser humano se expõe como um grande alerta relacionado à extinção de uma população (ROSA et al.,2017).

Não obstante, Decourtye et al. (2004) destaca que a utilização de agrotóxicos, fungicidas e pesticidas degradam significativamente a atividade melífera de qualquer espécie de abelhas, seja diretamente, afetando o olfato e a memorização, assim como causando irritabilidade e a perda de seu senso de direção. Afeta indiretamente também o processo de forrageamento, coleta de pólen e néctar devido aos resíduos químicos indesejáveis. Uma vez dentro da colmeia, conforme Pettis et al. (2013), tais substâncias podem acarretar a má formação de larvas e, por consequência, sua morte precoce, da mesma maneira como enfraquecendo seu sistema imunológico, abrindo brechas para a ação de predadores naturais das abelhas.

Em decorrência do risco de extinção dos Meliponíneos, grupo das ASF, várias espécies são preservadas por pessoas em locais denominados meliponários, que podem ser instalados na zona rural ou urbana. Palumbo (2015) destaca que as abelhas do gênero Apis são bastante conhecidas por possuírem ferrão. Já as ASF possuem o ferrão atrofiado, logo, são consideradas abelhas sociais, pois não representam ameaça aos humanos ou animais, facilitando assim o processo de manejo. Para o abrigo destas espécies nos meliponários, em sua maioria são utilizadas caixas de madeira com especificidades técnicas para cada colônia, o que possibilita a reprodução de novas colônias através das divisões de colônias bem estabilizadas, contribuindo assim com a sobrevivência das espécies.

Palumbo (2015) lembra que para produzir os suprimentos necessários à manutenção de colônias, as abelhas coletam pólen, néctar e resinas de plantas e flores produzindo com isso o mel, o própolis e o geoprópolis, além de reproduzirem naturalmente novas colônias. É na dinâmica de coleta fora da colmeia, que está o principal risco para as abelhas, elas podem ser afetadas por agentes climáticos, predadores, ação de resíduos poluentes e, principalmente, a contaminação por agrotóxicos, em especial, os inseticidas.

Neste ponto, o papel das instituições de ensino, pesquisa e extensão, como é o caso do Instituto Federal do Paraná (IFPR), é de educar e socializar os conhecimentos produzidos cientificamente, compartilhando as experiências, as técnicas e as descobertas científicas para a preservação não só das abelhas, mas de todo o meio ambiente. Não obstante, a missão do IFPR, segundo o Plano de Desenvolvimento Institucional 2019-2023 (IFPR, 2018, p. 23) é "Promover a educação profissional, científica e tecnológica, pública, gratuita e de excelência, por meio do

Revista Extensão \& Cidadania, v. 9, n. 15, p. 187-198, jan./jun. 2021. 
ensino, pesquisa e extensão, visando à formação integral de cidadãos críticos, empreendedores, comprometidos com a sustentabilidade e com o desenvolvimento local e regional."

E por meio da extensão que a universidade influencia e também é influenciada pela comunidade, ou seja, há uma troca de valores entre a universidade e o meio. A extensão aproxima o estudante do seu futuro profissional, incorpora contextos e reflete suas práticas enquanto sujeito de transformação da sociedade (SILVA, 2015).

Para Abílio e Guerra (2005), a escola, tendo em vista a importância que exerce no processo de formação social, cultural, humana e ética da sociedade, se apresenta como um dos locais mais propícios para o desenvolvimento de atividades com enfoque educativo relacionado ao ambiente em que vivemos. É por esta formação que possibilitamos às gerações futuras uma sociedade mais justa e sustentável.

Considerando que promover educação é a principal razão de ser do IFPR, várias ações de natureza de ensino, pesquisa e extensão podem ser levadas à comunidade escolar e compartilhar o que o conhecimento científico recomenda sobre os fatos e fenômenos que vêm ocorrendo em nossa sociedade. Para isto, as ações de extensão são fundamentais e necessárias para que o IFPR cumpra esta missão.

A educação ambiental como temática a ser desenvolvida nas escolas é prevista na Lei de Diretrizes e Base da Educação Nacional (LDB) no 9.394/1996 (BRASIL, 1996) e regulamentada na Base Nacional Comum Curricular (BNCC) (BRASIL, 2018), que "Para formar esses jovens como sujeitos críticos, criativos, autônomos e responsáveis, cabe às escolas de Ensino Médio proporcionar experiências e processos que lhes garantam as aprendizagens necessárias para a leitura da realidade, o enfrentamento dos novos desafios da contemporaneidade (sociais, econômicos e ambientais)" (BRASIL, 2018).

Neste ponto, ações mediadas pelo IFPR, como as que propõe o projeto Quintais de Mel, contribuem para reflexão sobre os principais desafios enfrentados na construção de uma sociedade mais justa e comprometida com a sustentabilidade. Portanto, manter o diálogo, estimular o debate junto à comunidade que esta instituição atende.

\section{Metodologia}

Para contribuir com a manutenção e sustentabilidade do ecossistema, a estratégia de ação do projeto é promover a educação ambiental, cuja própria população seja a protagonista

Revista Extensão \& Cidadania, v. 9, n. 15, p. 187-198, jan./jun. 2021. 
do processo. O nome "Quintais de Mel” vem ao encontro desta metodologia, inicialmente chegando até essa população por meio dos estudantes e, por fim, com aqueles que eles mantêm contato. Se cada cidadão possuir uma colônia de ASF em casa, abre-se uma série de possibilidades para promover a educação ambiental. Deste modo, incentivar a criação destes insetos dentro do ambiente urbano e rural e promover informações e conhecimentos voltados à criação, manutenção e preservação das ASF no município e região são algumas das estratégias metodológicas, propostas nas quatro fases do desenvolvimento do Projeto Quitais de Mel.

A primeira fase trata-se da estruturação de um meliponário urbano para construção de armadilhas, capturas e manejo das colônias das ASF, além do plantio de mudas de espécies arbóreas nativas e melíferas da Floresta Estacional Semidecidual (FES) do Paraná; a segunda fase é promover ações educativas nas escolas do município de Assis Chateaubriand, como oficinas, palestras e workshops sobre a temática em questão; a terceira fase é estimular a população atendida a criar abelhas nos próprios quintais de suas casas, ou seja, os pais dos estudantes atendidos serão incentivados a criar as abelhas por meio da mediação dos próprios filhos e a quarta e última etapa consiste em capacitar meliponicultores de Assis Chateaubriand para a produção de abelhas nativas sem ferrão no ambiente urbano e rural.

\section{Resultados e discussão}

O Projeto Quintais de Mel teve início no segundo semestre de 2019 por meio de uma oficina para confecção de iscas pet realizada no IFPR Campus Assis Chateaubriand. Nesta oportunidade, participaram da oficina os estudantes e membros do projeto: Clara Jamilly Lacerda Gianini; Beatris Freitas Mestriner e Laiz Freitas Mestriner, e, como instrutor, o professor Tiago Amaral. Na sequência, o grupo participou de uma palestra na Universidade Tecnológica Federal do Paraná, na cidade de Toledo - PR, cujo tema foi "A importância das abelhas para polinização".

Encerrando o ano de 2019, o projeto promoveu em dezembro, no IFPR Campus Assis Chateaubriand, o $1^{\mathrm{o}}$ Encontro de Meliponicultores de Assis Chateaubriand, trazendo uma palestra organizada em três temas centrais, cada um com um orador: Conhecendo as Abelhas Sem Ferrão, com Tiago Amaral; Regulamentação da Criação e Transporte das abelhas sem ferrão, com Alexandre Alves e Importância das abelhas para o meio ambiente, com Nivaldo Luiz.

Revista Extensão \& Cidadania, v. 9, n. 15, p. 187-198, jan./jun. 2021. 
No primeiro trimestre de 2020, as atividades no IFPR foram fortemente afetadas pelo fato da instalação global da pandemia do coronavírus, deste modo, o primeiro semestre de 2020 registrou poucas atividades do Quintais de Mel. Já para o segundo semestre de 2020, o projeto expandiu suas atividades por meios on-line, promovendo videochamadas entre os membros, a construção de um site, a criação de um canal do YouTube e perfis nas redes sociais Facebook e Instagram.

Configurou-se no grupo a sistemática de reuniões semanais por meio de videochamada quando em cada reunião uma nova meta semanal foi traçada. Como parte do resultado desta ação, temos a apresentação dos conteúdos desenvolvidos apresentados no site do projeto, conforme demonstra o Quadro 1:

\section{Quadro 1 - Atividades realizadas no Projeto Quintais de Mel}

\begin{tabular}{|c|c|c|}
\hline Título da atividade & Descrição & Link para acesso \\
\hline $\begin{array}{c}1^{\circ} \text { Encontro de } \\
\text { Meliponicultores de } \\
\text { Assis Chateaubriand - } \\
\text { PR }\end{array}$ & Evento promovido pelo projeto & $\begin{array}{l}\text { https://quintaisdemel.com/2019/12/ } \\
\text { 04/1o-encontro-de- } \\
\text { meliponicultores-de-assis- } \\
\text { chateaubriand-pr/ }\end{array}$ \\
\hline $\begin{array}{l}\text { Participação na VI Feira } \\
\text { de Ensino, Pesquisa, } \\
\text { Extensão e Inovação }\end{array}$ & Participação em evento científico & $\begin{array}{l}\text { https://quintaisdemel.com/2020/09/ } \\
\text { 29/participacao-na-vi-feira-de- } \\
\text { ensino-pesquisa-extensao-e- } \\
\text { inovacao/ }\end{array}$ \\
\hline $\begin{array}{l}\text { Live de apresentação do } \\
\text { projeto e oficinas }\end{array}$ & $\begin{array}{l}\text { Transmissão ao vivo pelo } \\
\text { YouTube }\end{array}$ & $\begin{array}{l}\text { https://quintaisdemel.com/2020/10/ } \\
\text { 13/live-de-apresentacao-do-projeto- } \\
\text { e-oficinas/ }\end{array}$ \\
\hline Plantas para ASF & $\begin{array}{l}\text { Lista de plantas para abelhas sem } \\
\text { ferrão disponível no site do } \\
\text { projeto }\end{array}$ & https://quintaisdemel.com/plantas/ \\
\hline $1^{\circ}$ Quintal de Mel & $\begin{array}{l}\text { Registro em vídeo da entrega de } \\
\text { colônia para o primeiro quintal de } \\
\text { mel do projeto }\end{array}$ & $\begin{array}{l}\text { https://quintaisdemel.com/2020/12/ } \\
\text { 02/1o-quintal-de-mel/ }\end{array}$ \\
\hline $\begin{array}{l}\text { Meliponário Macedo - } \\
\text { Toledo - PR }\end{array}$ & $\begin{array}{l}\text { Registro em vídeo do meliponário } \\
\text { e entrevista com meliponicultor }\end{array}$ & $\begin{array}{l}\text { https://quintaisdemel.com/2020/12/ } \\
\text { 04/meliponario-macedo-toledo-pr/ }\end{array}$ \\
\hline $\begin{array}{l}\text { Repasse de materiais e } \\
\text { troca de experiências - } \\
\text { Nelson Dapieve }\end{array}$ & $\begin{array}{l}\text { Registro em vídeo da entrega de } \\
\text { atrativo, cera mista e apostilas }\end{array}$ & $\begin{array}{l}\text { https://quintaisdemel.com/2020/12/ } \\
\text { 06/repasse-de-materiais-e-troca-de- } \\
\text { experiencias-nelson-dapieve/ }\end{array}$ \\
\hline
\end{tabular}

Fonte: Elaboração dos autores (2021).

Revista Extensão \& Cidadania, v. 9, n. 15, p. 187-198, jan./jun. 2021. 
Além desses conteúdos listados, o site apresenta mais postagens referentes à confecção de isca; tipos de caixa para cada espécie de abelhas,; alimentação de abelhas,; processo de nidificação e enxameação, além de transferência das abelhas das iscas pet para as caixas racionais. Todo conteúdo listado é público, gratuito e acessível por meio do site ou por meio das redes sociais do projeto.

Figura 1 - Transferência de abelhas jataí, feita pelos estudantes

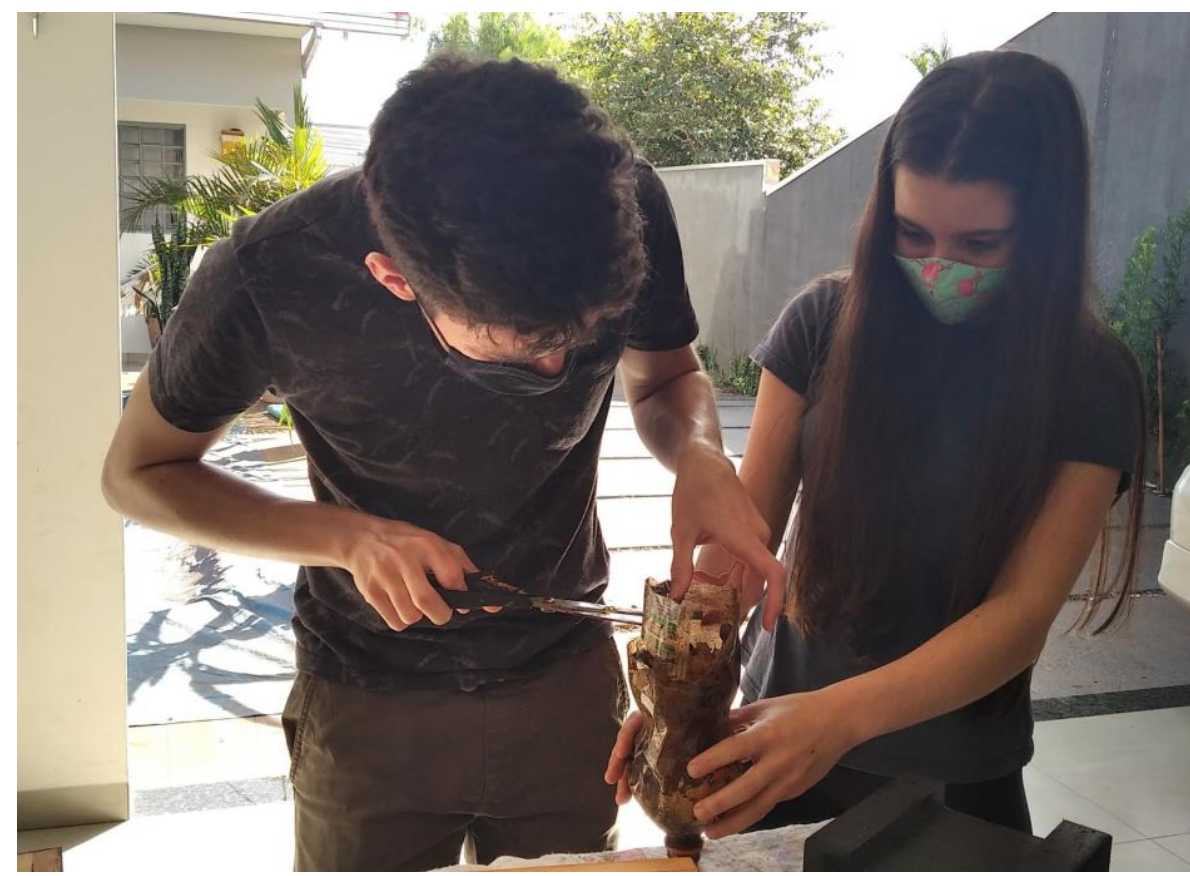

Fonte: Acervo dos autores (2021).

Nas atividades on-line, os membros do projeto atingiram o knowhow necessário, além da aquisição dos equipamentos adequados, direcionando assim grande parte do seu foco na produção de vídeos explicativos. Para organização destes vídeos, adotou-se o site do projeto juntamente com a plataforma YouTube, que permite acrescentar partes em texto no conteúdo no vídeo publicado. O YouTube permite o acesso irrestrito para todos usuários com internet, dispensando inclusive o registro do usuário na rede social (login). Para mais, permite aos membros do projeto acesso aos registros dos dados de cada um dos vídeos, viabilizando a avaliação de como o vídeo foi recebido pelo público. O Quadro 2 demonstra a soma dos dados de todos os vídeos do canal até março de 2021.

Revista Extensão \& Cidadania, v. 9, n. 15, p. 187-198, jan./jun. 2021. 
Quadro 2 - Dados sobre os vídeos do projeto no YouTube

\begin{tabular}{|l|c|}
\hline \multicolumn{1}{|c|}{ Categoria } & Informação \\
\hline Total de visualizações dos vídeos & 1259 \\
\hline Total de visualizações de inscritos no canal & 441 \\
\hline Total de visualizações de não inscritos no canal & 818 \\
\hline $\begin{array}{l}\text { Total de horas de reprodução dos vídeos do } \\
\text { canal }\end{array}$ & $57,8 \mathrm{~h}$ \\
\hline Total de vídeos no canal & 24 \\
\hline Total de "curtidas" nos vídeos do canal & 135 \\
\hline Total de comentários nos vídeos do canal & 65 \\
\hline
\end{tabular}

Fonte: Elaboração dos autores (2021).

Além das atividades descritas, foram realizadas capturas de algumas colônias de ASF, atualmente, o projeto realizou a aquisição de 3 colônias de abelhas da espécie Tetragonisca angustula (Jataí) e 3 colônias da espécie Plebeia droryana (Mirim), através da técnica de captura com armadilha pet, como sugere Palumbo (2015). Estas serão utilizadas para fins didáticos e, possivelmente, doadas para os participantes do projeto.

\section{Considerações finais}

Em meio às atividades de ensino do IFPR campus Assis Chateaubriand, nasceu o “Quintais de Mel”, formalizado como uma ação de extensão, que apresenta uma ferramenta bastante dinâmica para abordar o tema das ASF. Ao utilizar uma metodologia prática e conectada com as redes sociais, o objetivo de promover a educação ambiental está se concretizando a cada dia. Mesmo com a paralisação das atividades presenciais da maioria das instituições de ensino no país, decorrente da pandemia provocada pelo coronavírus, encontramos na extensão e nos recursos tecnológicos digitais e online, uma metodologia para atingirmos parcialmente o grande objetivo do projeto, que é a divulgação do conhecimento.

Parte do público do projeto, os estudantes e seus familiares, pode ter acesso aos conteúdos produzidos e com ele fazer parte dos beneficiados do projeto. A partir da relação que se estabelece entre esse público, muitos passam a se interessar pelas abelhas nativas sem ferrão e a procura por estes insetos, bem como os cuidados com a criação, torna-se motivo para a

Revista Extensão \& Cidadania, v. 9, n. 15, p. 187-198, jan./jun. 2021. 
busca de mais conhecimento, contudo, é importante ter sempre a percepção da necessidade de preservação.

O outro ponto fundamental que o projeto promove é a possibilidade do público alvo receber a doação de uma colônia de abelha nativa. A partir desse instante, o sujeito passa a buscar mais conhecimento sobre o manejo das abelhas, inicia-se um processo de plantio de plantas melíferas para alimentação dos insetos e, com isso, a expectativa de cada vez mais e mais agentes multiplicadores da ideia de conservação e preservação.

\section{Referências}

ABÍLIO, Francisco José Pegado; GUERRA, Rafael Angel Torquemada (org.). A questão ambiental no ensino de Ciências e a formação continuada de professores de ensino fundamental. João Pessoa: UFPB/FUNAPE, 2005.

BOFF, Leonardo. Sustentabilidade: o que é: o que não é. Rio de Janeiro: Vozes, 2012.

BRASIL. Ministério do Meio Ambiente. Conselho Nacional do Meio Ambiente (CONAMA). Resolução no 496, de 19 de agosto 2020. DOU, Brasília - DF, 2020. Disponível em: https://www.in.gov.br/en/web/dou/-/resolucao-n-496-de-19-de-agosto-de-2020-273217120 Acesso em: 30 set. 2020.

BRASIL. Ministério da Educação e do Desporto. Secretaria de Educação Fundamental. Parâmetros Curriculares Nacionais Terceiro e Quarto Ciclos do Ensino Fundamental: introdução aos parâmetros curriculares nacionais. Brasília, DF: MEC/SEF, 1998.

BRASIL. Lei no 7.802, de 11 de julho de 1989. Disponível em: http://www. planalto.gov.br/ccivil_03/leis/17802.htm. Acesso em: 4 maio 2021.

BRASIL. Ministério da Educação; Secretaria de Educação Básica; Conselho Nacional de Educação; Câmara de Educação Básica. Base Nacional Comum Curricular. Brasília: MEC, 2018. Disponível em: http://basenacionalcomum.mec.gov.br/abase/\#médio Acesso em: 6 maio 2020.

BRASIL. Lei de Diretrizes e Base da Educação Nacional (LDB). Lei no 9.394, de 20 de dezembro de 1996. Brasília, DF: MEC, 1996.

DECOURTYE, Axel et al. Imidacloprid impairs memory and brain metabolism in the honeybee (Apis mellifera L.). Pesticide Biochemistry and Physiology, v. 78, n. 2, p. 83-92, 2004.

FERREIRA, Aurélio Buarque de Holanda. Dicionário Aurélio da Língua Portuguesa. 5. ed. Curitiba, Paraná: Positivo - Livros, 2010.

Revista Extensão \& Cidadania, v. 9, n. 15, p. 187-198, jan./jun. 2021. 
IFPR. Instituto Federal do Paraná. Plano de desenvolvimento institucional: 2019-2023. Curitiba, 2018. Disponível em: http://info.ifpr.edu.br/wp-content/uploads/PDI-2019-2023Revisao-2020.pdf . Acesso em: 7 maio 2021.

PALUMBO, Hermes Neri. Nossas brasileirinhas: as abelhas nativas. Programa cultivando água boa. Curitiba, 2015. Disponível em:

http://www.cpra.pr.gov.br/arquivos/File/cartilhameliponideos.pdf. Acesso em: 6 maio 2020.

PARANÁ. Instituto Ambiental do Paraná (IAP). Sistema de Informações Ambientais (SIA). Portaria IAP no 006, de 19 de janeiro de 2019. Curitiba, 2019. Disponível em: http://celepar7.pr.gov.br/sia/atosnormativos/form_cons_ato1.asp?Codigo=4083 Acesso em: 2 dez. 2020.

PETTIS, Jeffery Stuart et al. Crop pollination exposes honey bees to pesticides which alters their susceptibility to the gut pathogen Nosema ceranae. PloS one, v. 8, n. 7, e70182, 2013.

ROSA, Joatan Machado et al. Polinizadores em perigo: Por que nossas abelhas estão desaparecendo? In: SIMPÓSIO INTERNACIONAL DE CIÊNCIAS, SAÚDE E TERRITÓRIO, IV, 2017, Lages, SC. Anais eletrônicos. Lages: UNIPLAC, 2017. p. 1112 1118. Disponível em:

http://www.simposioppgas.com.br/downloads/ANAIS_SIMPOSIO2017.pdf. Acesso em: 7 maio 2021.

SILVA, Marivânia Rufato. Avaliação da sustentabilidade dos agroecossistemas de agricultores familiares que atuam na feira-livre de Pato Branco - PR. 2015. $179 \mathrm{f}$ Dissertação (Mestrado em Desenvolvimento Regional) - Universidade Tecnológica Federal do Paraná, Pato Branco, 2015.

Recebido: 10.05.2021

Aceito: 21.06 .2021

Revista Extensão \& Cidadania, v. 9, n. 15, p. 187-198, jan./jun. 2021. 